JAHRBUCH FUR DIE GESCHICHTE MITTEL- UND OSTDEUTSCHLANDS

BAND 18 



\title{
JAHRBUCH FÜR DIE GESCHICHTE MITTEL- UND OSTDEUTSCHLANDS
}

\author{
PUBLIKATIONSORGAN DER \\ HISTORISCHEN KOMMISSION ZU BERLIN
}

\author{
HERAUSGEGEBEN VON \\ WILHELM BERGES HANS HERZFELD \\ HENRYK SKRZYPCZAK \\ IM AUFTRAGE DES \\ FRIEDRICH-MEINECKE-INSTITUTS \\ DER FREIEN UNIVERSITÄT BERLIN
}

BAND 18

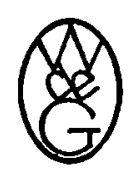

1969

WALTER DE GRUYTER \& CO. - BERLIN

vormals G. J. Göschen'sche Verlagshandlung · J. Guttentag, Verlagsbuchhandlung Georg Reimer - Karl J. Trübner - Veit \& Comp. 


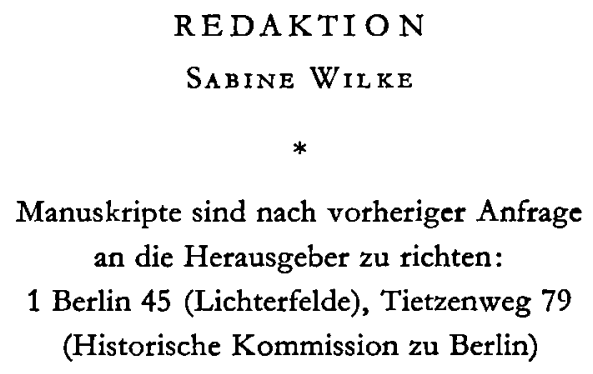

Bände 1-10 erschienen im Max Niemeyer Verlag, Tübingen

(C)

Archiv-Nr. 481970/1

Copyright 1970 by Walter de Gruyter \& Co. · vormals G. J. Göschen'sche Verlagshandlung J. Guttentag, Verlagsbuchhandlung · Georg Reimer · Karl J. Trübner · Veit \& Comp.

Printed in Germany - Alle Rechte der Ubersetzung, des Nachdrucks, der photomechanischen Wiedergabe und der Anfertigung von Mikrofilmen auch auszugsweise - vorbehalten.

Satz und Druck: W. Büxenstein GmbH., Berlin 